\title{
Chinese Expert Consensus on the Nucleic Acid Detection of SARS-CoV-2
}

\begin{abstract}
Zijie Liu ${ }^{1,2 \#} \wedge$, Yongqing Tong ${ }^{3 \#}$, Jun $\mathrm{Wu}^{4 *}$, Lutao $\mathrm{Du}^{5 \#}$, Chaojun $\mathrm{Wei}^{6 *}$, Wei Cui ${ }^{7}$, Yongtong $\mathrm{Cao}^{8}$, Ming Chen ${ }^{9}$, Zhen Cai ${ }^{10}$, Wei Chen ${ }^{11}$, Haitao Ding ${ }^{12}$, Ming Guan ${ }^{13}$, Wei Guo ${ }^{14}$, Chunfang Gao ${ }^{15}$, Xiaoke $\mathrm{Hao}^{16}$, Chengjin $\mathrm{Hu}^{17}$, Shan Huang ${ }^{18}$, Yanfang Jiang ${ }^{19}$, Jinming $\mathrm{Li}^{20}$, Ping $\mathrm{Li}^{21}$, Zhuo $\mathrm{Li}^{22}$, Liang Ming ${ }^{23}$, Shiyang Pan ${ }^{24}$, Zuojun Shen ${ }^{25}$, Jianrong Su ${ }^{26}$, Ziyong Sun ${ }^{27}$, Hui Wang ${ }^{28}$, Junjun Wang ${ }^{29}$, Bin Xu ${ }^{30}$, Nong Yu ${ }^{31}$, Lei Zheng ${ }^{10}$, Yi Zhang ${ }^{32}$, Xin Zhang ${ }^{33}$, Ying Zhang ${ }^{34}$, Yong Duan ${ }^{1,2}$, Chengbin Wang ${ }^{34}$; on behalf of the Chinese Society of Laboratory Medicine
\end{abstract}

${ }^{1}$ Yunnan Key Laboratory of Laboratory Medicine, Kunming, China; ${ }^{2}$ Department of Laboratory Medicine, First Affiliated Hospital of Kunming Medical University, Kunming, China; ${ }^{3}$ Laboratory Medicine Center, Renmin Hospital of Wuhan University, Wuhan, China; ${ }^{4}$ Department of Clinical Laboratory, Shanghai General Hospital Jiading Branch, Shanghai, China; ${ }^{5}$ Laboratory Medicine Center of The Second Hospital of Shandong University, Jinan, China; ${ }^{6}$ The Institute of Clinical Research and Translational Medicine, Gansu Provincial Hospital, Lanzhou, China; ${ }^{7}$ Department of Laboratory Medicine, Cancer Hospital Chinese Academy of Medical Sciences, Beijing, China; ${ }^{8}$ Laboratory Department of China-Japan Friendship Hospital, Beijing, China; ${ }^{9}$ Laboratory Department of Southwest Hospital, Chongqing, China; ${ }^{10}$ Department of Laboratory Medicine, Nanfang Hospital of Southern Medical University, Guangzhou, China; ${ }^{11}$ Department of Laboratory Medicine, the First Affiliated Hospital of Xi'an Jiaotong University, Xi'an, China; ${ }^{12}$ Department of Laboratory Medicine, People's Hospital of Inner Mongolia Autonomous Region, Hohhot, China; ${ }^{13}$ Department of Laboratory Medicine, Huashan Hospital, Fudan University, Shanghai, China; ${ }^{14}$ Department of Laboratory Medicine, Zhongshan Hospital, Fudan University, Shanghai, China; ${ }^{15}$ Department of Laboratory Medicine, Eastern Hepatobiliary Surgery Hospital, Second Military Medical University, Shanghai, China; ${ }^{16}$ Department of Laboratory Medicine, Xijing Hospital, Air Force Military Medical University, Xi'an, China; ${ }^{17}$ Department of Laboratory Diagnosis, 960th Hospital of Chinese PLA, Jinan, China; ${ }^{18}$ Guizhou Province Center for Clinical Laboratory, Guiyang, China; ${ }^{19}$ Gene Diagnostic Center of the First Hospital of Jilin University, Changchun, China; ${ }^{20}$ National Center for Clinical Laboratories, Beijing, China; ${ }^{21}$ Medical Laboratory and Pathology Center, the First Affiliated Hospital of Hunan University of Traditional Chinese Medicine, Changsha, China; ${ }^{22}$ Department of Laboratory Medicine, the First Affiliated Hospital of Xi'an Medical College, Xian, China; ${ }^{23}$ Department of Laboratory Medicine, the First Affiliated Hospital of Zhengzhou University, Zhengzhou, China; ${ }^{24}$ Department of Laboratory Medicine, the First Affiliated Hospital of Nanjing Medical University, Nanjing, China; ${ }^{25}$ Scientific Research Department of the First Affiliated Hospital of University of Science and Technology of China, Hefei, China; ${ }^{26}$ Department of Laboratory Medicine, Beijing Friendship Hospital, Capital Medical University, Beijing, China; ${ }^{27}$ Department of Laboratory Medicine, Tongji Hospital, Tongji Medical College, Huazhong University of Science and Technology, Wuhan, China; ${ }^{28}$ Department of Laboratory Medicine, Peking University People's Hospital, Beijing, China; ${ }^{29}$ Department of Laboratory Medicine, Eastern Theater General Hospital; Nanjing, China; ${ }^{30}$ Provincial Clinical Inspection Center of Jiangsu Cancer Hospital, Nanjing, China; ${ }^{31}$ Laboratory of Suzhou Branch of Xinhua Hospital Affiliated to Shanghai Jiaotong University, Suzhou, China; ${ }^{32}$ Department of Laboratory Medicine, Qilu Hospital of Shandong University, Jinan, China; ${ }^{33}$ Department of Laboratory Medicine of Xinjiang Production and Construction Corps Hospital, Urumqi, China; ${ }^{34}$ Department of Clinical Laboratory Medicine, the First Medical Center, Chinese PLA General Hospital, Beijing, China

"These authors contributed equally to this work.

Correspondence to: Chengbin Wang. Department of Clinical Laboratory Examination Center, Chinese PLA General Hospital, Beijing 100853, China. Email: wangcb301@126.com; Yong Duan. Department of Laboratory Medicine, First Affiliated Hospital of Kunming Medical University, Kunming 650031, China. Email: duanyong7@139.com.

\begin{abstract}
The coronavirus disease 2019 (COVID-19) has already become a pandemic wherein the infection's timely diagnosis has proven beneficial to patient treatment and disease control. Nucleic acid detection has been the primary laboratory diagnostic method for the detection of SARS-CoV-2. To ensure laboratory staff safety and quality nucleic acid testing, the Chinese Society of Laboratory Medicine formulated this consensus, based on the Chinese National Recommendations and previous literature for
\end{abstract}

^ORCID: 0000-0002-4734-5554. 
nucleic acid detection. A working group comprises 34 hospital professionals experience with real-time polymerase chain reactions (PCR) testing for SARS-CoV-2 drafted guidance statements during online discussions. A modified Delphi methodology was used in forming a consensus among a wider group of hospital professionals with SARS-CoV-2 detection experience. Guidance statements were developed for four categories: (I) specimen type, priority, collecting, transportation and receiving; (II) nucleic acid isolation and amplification; (III) quality control; (IV) biosafety management and decontamination. The modified Delphi voting process included a total of 29 guidance statements and final agreement. Consensus was reached after two rounds of voting. Recommendations were established for the detection of SARS-CoV-2 using real time PCR testing based on evidence and group consensus. The manuscript was evaluated against The Appraisal of Guidelines for Research \& Evaluation Instrument (AGREE II) and was developed to aid medical laboratory staff in the detection of the ribonucleic acid (RNA) of SARS-CoV-2.

Keywords: SARS-CoV-2; coronavirus disease 2019 (COVID-19); nucleic acid; polymerase chain reaction (PCR)

Submitted May 19, 2020. Accepted for publication Nov 15, 2020.

doi: $10.21037 /$ atm-20-4060

View this article at: http://dx.doi.org/10.21037/atm-20-4060

\section{Introduction}

Since the outbreak of COVID-19, the number of infected people has been increasing rapidly worldwide (1-4); hence, rapid and effective laboratory diagnostic testing has been essential for a timely diagnosis of confirmed and suspected patients. The detection of SARS-CoV-2 using nucleic acid provides direct evidence for the diagnosis $(5,6)$. Because transmission routes and the underlying pathogenicity of SARS-CoV-2 have not yet been clarified, laboratory staff face a high risk of infection during the testing process. In addition, because the gene structure of SARS-CoV-2 is different from that of other RNA viruses, the testing process, quality control, and biosafety measures have been adjusted accordingly. In order to guide laboratory testing, this consensus was developed on the recommendations of the National Health Commission of China, literature, and expert opinion in Wuhan, China.

This consensus was developed for use in laboratories using nucleic acid in the detection of SARS-CoV-2, especially those using real-time polymerase chain reaction (PCR).

The following article was drafted in accordance with the AGREE II reporting checklist (available at http://dx.doi. org/10.21037/atm-20-4060).

\section{Methods}

\section{Development of guidance statements}

The Consensus of Nucleic Acid Detection of SARS-CoV-2 was formulated to fight against the COVID-19 epidemic and provide suggestions for medical laboratories. At the beginning of the outbreak, there was limited information regarding SARS-CoV-2; therefore, a working group comprised of experienced molecular testing professionals was convened to formulate this consensus. The group included molecular testing experts in China specializing in biosafety and quality management. Issues were discussed online and a list of questions developed, then grouped into four areas of clinical focus (Table 1, Table S1). It should be noticed that the guidance statements in this consensus were based on both literature and clinical experience. The working group also deemed it necessary to provide additional clarity in the supporting text and footnotes to supplement their statements, as new testing information became available.

Guidance statements were developed based on both relevant literature, the regulations of The National Health Commission of the People's Republic of China and supplemented with appropriate expert opinion. To maintain independence from commercial organizations, none were 
Table 1 Areas of clinical focus

Specimen type and priority, collecting, transportation and receiving (Table 2)

Nucleic acid isolation and amplification (Table 3)

Quality control (Table 4)

Biosafety management and decontamination (Table 5)

invited to participate in the development of this consensus. To ensure the applicability of the statements, a review was conducted by the Chinese Society of Laboratory Medical Experts. Specific advice is detailed in the discussion.

\section{Literature review methodology}

The literature review examined what specimens could be used in the detection of SARS-CoV-2 along with what priority a particular specimen should be given; furthermore, deactivation of the virus and biosafety management in specimen handling were also examined. Given the limited availability of published data during the research period, especially for real-time PCR testing in the detection of SARS-CoV-2, and as this consensus was not related to the benefits and side-effects of patients, the evidence regarding such was not assessed.

The keyword search incorporated Medical Subject Headings and free-text keywords, listed in Table S2. The literature search was conducted using PubMed as the primary database, along with WANFANG med online, CNKI, VIP databank, and other online sources which included the Chinese Health Commission website (http:// www.nhc.gov.cn; http://www.samr.gov.cn/), Selected articles related to SARS-CoV-2 or other RNA viruses, included both articles in Chinese and English. Search strategies are outlined in Table S3. The evidence for the questions were reviewed by the members of the working group and used to develop guidance statements. Evidence levels were assessed using Oxford Centre for Evidence-Based Medicine criterion (see Table S4a).

\section{Consensus process}

A modified Delphi methodology was applied among the working group's members to develop a consensus on the guidance statements. Statements were put forward based on both literature and expert opinions. They were sent to members of the working group from the 34 hospitals in China for discussion (Tables S4 and S5). Consensus was defined as an agreement of $>75 \%$ on a specific statement. If consensus was not reached, it would be revised by the working group for a maximum of three rounds before a decision of "no agreement". Based on comments received during the first round of voting, the working group made a decision to update and revote on statements that reached a $75-85 \%$ consensus to improve their clarity $(7,8)$.

\section{Results}

A total of 29 guidance statements were voted on in the modified Delphi framework. The final statements are listed in Tables 2-5 and Tables S5,S6. A quick reference guide to all statements can be found in Table S7. In the first round of voting, 36 responses were received from 34 hospitals/ institutions. While consensus was reached on $36 / 36$ statements (Table S4b), four statements were at the threshold achieving $75-85 \%$ agreement. The working group opted to revise the four statements to improve clarity. They were sent for a second-round of voting, in which 36 responses were received from 33 hospitals/institutions. Consensus was achieved on all four statements (Table S5b); thus, a thirdround was not required. Please refer to Tables S4a,S4b for evidence levels assigned for the publications used to develop each of the guidance statements. These statements apply to the screening and diagnosis of patients with a suspected SARS-CoV-2 infection.

\section{Specimen type, priority, collecting, transportation and bandover}

\section{Specimen type and priority}

Optimal specimen choice was examined to improve the accuracy of detection. Sputum and bronchoalveolar lavage fluid (BALF) have proven to be the most suitable choice (9-11), but the patients with COVID-19 often do not have sputum and taking BALF has proven difficult. In addition, medical staff may face an increased risk infection when collecting sputum and BALF samples. It is recommended that in obtaining an acceptable specimen the order of priority should be given to a nasopharyngeal swab, followed by an oropharyngeal swab, sputum then BALF. Feces can be tested, controlling the source of infection (12). Blood tests 
Table 2 Guidance statements: specimen type and priority, collecting, transportation and handover

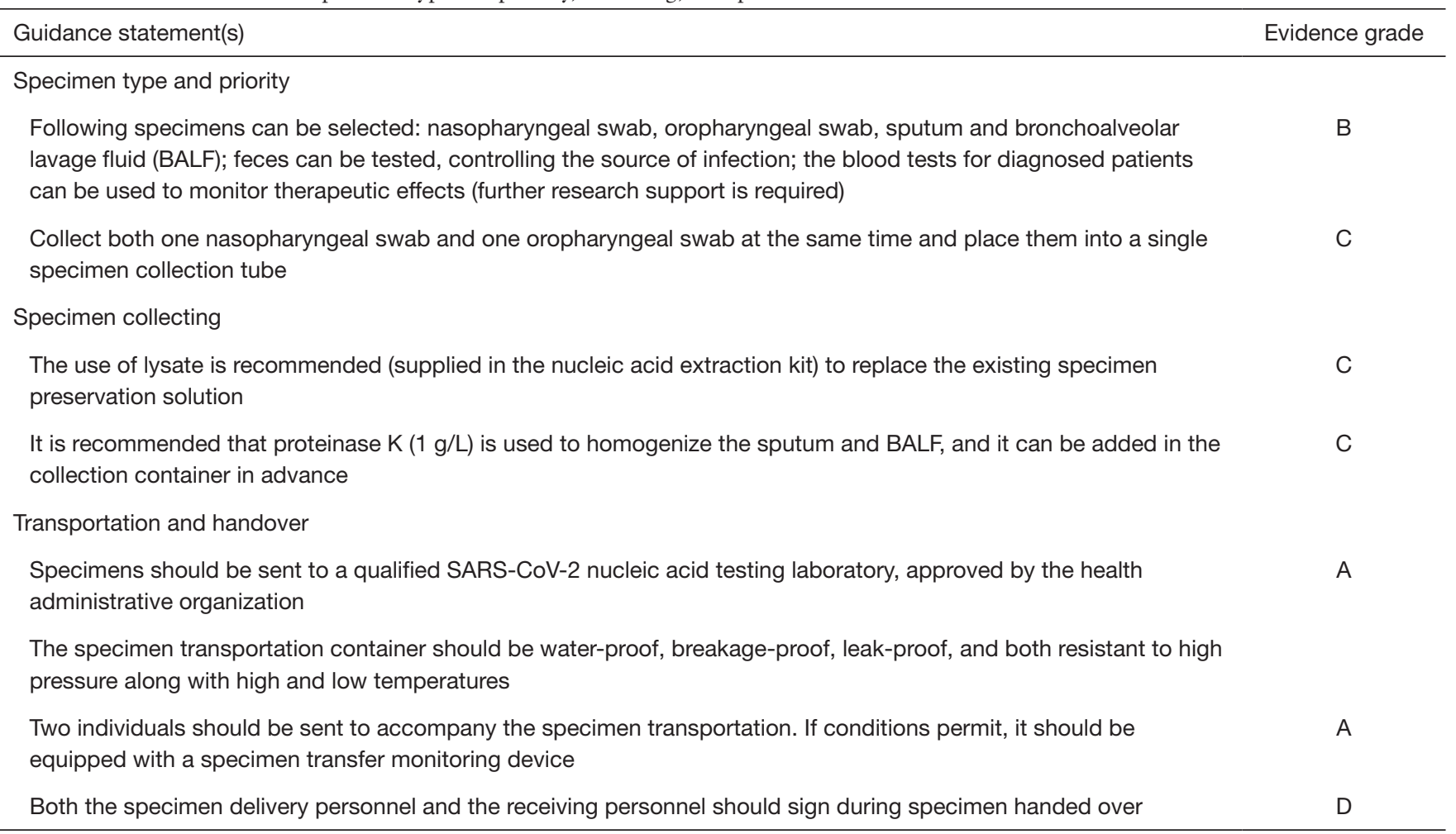

Table 3 Guidance statements and references: nucleic acid isolation and amplification

Guidance statement(s)
Virus inactivation
The virus can be inactivated by heating to a temperature of $56^{\circ} \mathrm{C}$ for $30 \mathrm{~min}$ or $60-65^{\circ} \mathrm{C}$ for $20 \mathrm{~min}$. The specimen
preservation solution should contain an RNA protectant
Nucleic acid isolation
Nasopharyngeal swab and oropharyngeal swab with cell lysate can be used directly for nucleic acid isolation. If
necessary, virus inactivation steps may be added
Sputum is incubated for 15 min at $55^{\circ} \mathrm{C}$ for homogenization. If proteinase $\mathrm{K}$ is not pre-added to the sputum
collection cup, this step should be performed after virus inactivation
Automated nucleic acid extraction methods are recommended
Amplification reagents
The amplification reagent should contain at least two sites of the SARS-CoV-2 gene (open reading frame 1a/b and
nucleocapsid protein or envelope protein E)
Results
The results should be reported as positive or negative


Table 4 Guidance statements and references: quality control

Guidance statement(s)
If cell lysate or proteinase $\mathrm{K}$ is added to the specimen collection tube, the expiration date and storage conditions
should meet the criteria
Specimens should be transported to the hospital within $2-4 \mathrm{~h}$ to prevent degradation of the RNA
The specimens should be processed promptly
Set a reagent control, positive control, negative and a positive quality control
Place in an ice bath for $3-5$ min or at room temperature for $>10$ min after heating or centrifuging for decreasing the
risk of aerosol
The cautious use of $75 \%$ ethyl alcohol is recommended

Table 5 Guidance statements and references: biosafety management and decontamination

\begin{tabular}{|c|c|}
\hline Guidance statement(s) & Evidence grade \\
\hline $\begin{array}{l}\text { Level three protection is recommended. If necessary, one can wear a waterproof apron or waterproof isolation } \\
\text { clothing }\end{array}$ & A \\
\hline All work regarding specimen treatment should be carried out in a biological safety cabinet with an efflux function & $\mathrm{D}$ \\
\hline $\begin{array}{l}\text { The waste generated during testing should be immediately transferred outside of the working area through the waste } \\
\text { passage. Three-layer medical waste packaging bags are recommended }\end{array}$ & A \\
\hline Terminal disinfection is carried out using a hydrogen peroxide disinfector or other methods & A \\
\hline $\begin{array}{l}\text { Protective clothing, shoe covers, gloves, and masks are sterilized with a } 75 \% \text { ethanol solution and collected in three } \\
\text { layers of medical waste packaging bags }\end{array}$ & A \\
\hline $\begin{array}{l}\text { The operator should dispose of waste promptly and this should be recorded. The waste should not be removed from } \\
\text { the laboratory without permission. Medical waste should be treated in accordance with the Administrative Measures } \\
\text { on Medical Wastes in Medical and Health Institutions }\end{array}$ & A \\
\hline
\end{tabular}

for diagnosed patients can be used to monitor therapeutic effects (further research support is required) (13).

\section{Specimen collecting}

(I) Nasopharyngeal swab: the nasopharyngeal swab should be collected from patients in the early-onset stage. Tilt the patient's head slightly backward. The distance between the tip of the nose and the ear lobe is precisely measured with a swab and marked with a finger. Insert the swab to the measured distance. Leave the swab in the nose for $15-30$ s, gently rotating $3-5$ times then immediately place it in the sample collection tube filled with $2 \mathrm{~mL}$ lysate (supplied in the nucleic acid extraction kit) or a cell preservation solution containing the RNase inhibitor (14).

(II) Oropharyngeal swab: the oropharyngeal swab should 
be collected from patients in the early-onset stage. It is recommended that a sterile flock swab be used for sampling by wiping the back wall of the pharynx with moderate force. During the process, touching the tongue should be avoided. The swab should be placed into the same collection tube as the Nasopharyngeal swab.

(III) Sputum: deep cough sputum should be collected in a disposable sterile screw-cap sampling cup containing $2 \mathrm{~mL}$ of proteinase $\mathrm{K}(1 \mathrm{~g} / \mathrm{L})(15,16)$, closing the container upon collection. The test should be conducted within $30 \mathrm{~min}$ if possible. If the specimen needs to be transported over a long distance, proteinase $\mathrm{K}$ should not be added in advance.

(IV) Bronchoalveolar lavage fluid (BALF): in the case of severe patients or patients with rapidly progressing pneumonia, the clinician should aseptically collect $\geq 5 \mathrm{~mL}$ BALF into a 50 - $\mathrm{mL}$ sterile container.

(V) Feces: for patients in the early-onset stage with gastrointestinal symptoms such as diarrhea, 3-5 g (soybean size) stool samples are collected in screwcapped specimen collection tubes containing $2 \mathrm{~mL}$ saline (RNase inhibitors added if possible).

(VI) Blood: blood could be collected from patients within 7 days of onset or those considered to have viremia. Usually, 2-4 $\mathrm{mL}$ blood samples are collected using vacuum blood vessels containing an ethylenediaminetetraacetic acid (EDTA) anticoagulant.

To increase the accuracy of detection both, one nasopharyngeal swab and one oropharyngeal swab should be both collected into a single collection tube at the same time (17).

\section{Specimen transportation}

Specimens should be sent to a qualified SARS-CoV-2 nucleic acid testing laboratory approved by the health administrative organization (18).

Transport should be done in a three-layer packaging system: inner container, along with middle, and outer packaging. They should be water-proof, breakage-proof, leak-proof, and be both resistant to high pressure along with high and low temperatures. Relevant biohazard labels, warnings, and prompts should be displayed on the transport containers and packaging materials. The leak-proof inner container is to be packaged with a biohazard symbol pasted on it and placed in the middle container. Infectious materials identification is placed on the outer packaging. A sufficient amount of absorbent material should be placed between the inner and middle containers. The middle container should be secured in a hard outer container, and gel ice packs should be placed between the middle and outer containers $(19,20)$.

If a specimen needs to be transported over a long distance, a "Qualified Transportation Certificate" should be processed in accordance with the "Management Regulations on the Transport of Highly Pathogenic Microorganisms (Poison) Species or Samples Infecting Humans" (21). SARS-CoV-2 specimens belong to category A, with the UN identification number UN2814. If transportation is by air, the packaging should also comply with the PI602 classification and packaging requirements of the International Civil Aviation Organization (ICAO) document Doc9284-AN/905 "Technical Rules for the Safe Transport of Dangerous materials by Air" (19,22).

Two individuals should be sent to accompany the transportation of the specimens (23). If conditions permit, shipping containers should be equipped with a specimen transfer monitoring device.

\section{Specimen handover}

Both the specimen delivery personnel and the receiving personnel should sign during the specimen handed over. Before receiving specimens, the outer packaging of the specimen transfer container is to be checked for damage, and the specimens should be stored in a designated refrigerator (24). If the specimens cannot be tested immediately, they may be stored at $4{ }^{\circ} \mathrm{C}$ for a short period (the total duration from the collection time should not be $>24 \mathrm{~h}$ ) or at $-70{ }^{\circ} \mathrm{C}$ for a prolonged period (17). Samples that have been refrigerated over 4 hours at 4 degrees may still be viable; yet, the rate of decay has not been documented. Further research is needed to study the rate of sample decay.

\section{Nucleic acid isolation and amplification}

\section{Virus inactivation}

It is recommended that a water bath be used for virus inactivation. The virus can be inactivated by heating to a temperature of $56^{\circ} \mathrm{C}$ for $30 \mathrm{~min}$ or $60-65^{\circ} \mathrm{C}$ for $20 \mathrm{~min}$ $(25,26)$. In order to prevent specimens from floating, a heavy object may be over-top of them. Specimens are to be agitated gently, once every 10 minutes.

\section{Nucleic acid isolation}

In order to ensure the safety of the personnel along with the 
purity and efficiency of nucleic acid extraction, automated nucleic acid extraction methods are recommended.

(I) Nasopharyngeal swab and oropharyngeal swab: specimens with cell lysate can be used directly for nucleic acid isolation. If necessary, virus inactivation steps can be added (19).

(II) Sputum: samples are incubated for $15 \mathrm{~min}$ at $55^{\circ} \mathrm{C}$ for homogenization (15). If proteinase $\mathrm{K}$ was not added in advance, this step should be performed after virus inactivation.

(III) BALF and feces: samples are individually placed into a sealed bag and should be agitated thoroughly to mix well.

(IV) Blood: plasma is obtained by centrifuging at $1,500 \times \mathrm{g}$ for $10 \mathrm{~min}$, and then incubated on ice for 3-5 min or at room temperature for $>10 \mathrm{~min}$. Subsequently, the nucleic acid is extracted.

\section{Amplification reagents}

The amplification reagent should contain at least two sites of the $S A R S-C O V-2$ gene (open reading frame $1 \mathrm{a} / \mathrm{b}$ and nucleocapsid protein or envelope protein E) (19).

\section{Results}

According to the Laboratory Testing Technical Guide of New Coronavirus Infection Pneumonia (19), the results should be reported as positive or negative and supply interpretation for each result, along with suggestions for the next steps.

(I) Positive results: ORF1ab gene and $N$ gene are both positive (19).

(II) Negative results: if the result shows no cycle threshold $(\mathrm{Ct})$ value or $\mathrm{Ct} \geq 40$ at the two detection sites (refer to the reagent manual for details), it can be reported as negative.

(III) Gray zone results: when the Ct value is between 37 and 40 , it is a gray zone result (refer to the reagent manual for details).

\section{Quality control}

\section{Specimen}

If the cell lysate or proteinase $\mathrm{K}$ is added to the specimen collection tube, the expiration date and storage conditions should meet the criteria.

Specimens should be transported and examined as soon as possible after collection, ideally within $2-4 \mathrm{~h}$. The transportation time should not exceed $24 \mathrm{~h}$ when transporting at $2-8{ }^{\circ} \mathrm{C}$. If the transportation time exceeds $24 \mathrm{~h}$, they should be stored and transported at $\leq-70{ }^{\circ} \mathrm{C}(17)$. Sputum, oropharyngeal, and nasopharyngeal swabs are preserved in homogenization agents or cell preserving agents, which might cause degradation of nucleic acids due to prolonged operation.

\section{Control and quality control}

(I) The reagent control contains only PCR amplification reagents.

(II) It is recommended that the nucleic acids of the positive samples be used as a positive control.

(III) As Nucleic acid may form an aerosol, for negative quality control, after each test 3-5 tubes containing $2 \mathrm{~mL}$ of sterile water should be placed in different positions at different working areas to monitor for airborne contaminants that could affect test results.

(IV) Samples with a lower viral load can be used as a positive quality control after inactivation. When the corresponding quality control materials are provided by the inter-room quality assessment agency, the laboratories should participate in the inter-room quality assessment.

Negative and positive quality control materials should be operated in parallel with the specimen testing (27).

\section{Cautious use of $75 \%$ ethanol}

For reasons of laboratory safety and to inhibit the effects of gene amplification, the cautious use of $75 \%$ ethyl alcohol is recommended.

\section{Aerosol formation}

In order to reduce the formation of aerosols, procedures should be performed gently during the specimen treatment. Subsequently, specimens can be placed in an ice bath for 3-5 min or at room temperature for $>10 \mathrm{~min}$, after heating or centrifuge.

\section{Optimizing work process}

Optimized working procedures are beneficial for detection. An expedited work process is conducive to reducing the degradation of nucleic acids. In order to reduce the crosscontamination of nucleic acids in the various sections of the laboratory, it is advisable to carry out SARS-CoV-2 nucleic 
acid testing through the division of labor and cooperation.

\section{Biosafety management and decontamination of nucleic acid}

\section{Personal}

Individuals involved in specimen collection should be trained and certified in biosafety as organized by the Department of Hospital Infection Management or Superior Management. Sample processing should be carried out at least by two or more individuals depending on the specimen numbers (23).

\section{Protective equipment}

It is recommended that individuals should use level three protection equipment during the whole process, including work clothes, disposable work hats, double gloves, protective clothes, KN95/N95 masks, or higher-level particulate protective masks or a powered air-purifying respirator, a protective face screen, work shoes or rubber boots and waterproof boot covers. If necessary, one may wear a waterproof apron or waterproof isolation clothing (20).

The work place for specimen collection should be equipped with garbage bins for infectious waste, medicine for emergency incidents, and appropriate ventilation to prevent the spread and infection of pathogenic microorganisms (28).

In order to deal with accidental spillage, the specimen transportation personnel should carry $75 \%$ ethanol.

\section{Handling specimens}

All work relating to the treatment of specimens should be carried out in a biological safety cabinet with an efflux function. The biosafety cabinet should be equipped with a waste bucket containing a $0.55-1 \%$ chlorine disinfectant. If possible, a layer of water-absorbent material should be spread on the operating surface of the biosafety cabinet.

\section{Disinfection}

A solution of $75 \%$ ethanol is used to spray the inner wall of the nucleic acid extractor and other parts of the equipment that can be treated with it, followed by irradiation with ultraviolet light for $30 \mathrm{~min}$ (20). A $75 \%$ ethanol or $0.55-1 \%$ chlorine-containing disinfectant is used to clean work surfaces, followed by UV irradiation for $30 \mathrm{~min}$ to sterilize the surface. The terminal disinfection is carried out using a hydrogen peroxide disinfector or other methods (29).

The frequency of floor disinfection can be determined according to the number of specimens, but at least once a week is recommended. Ground disinfection can be carried out using a $0.55-1 \%$ chlorine-containing disinfectant after ultraviolet disinfection.

\section{Waste disposal}

Protective equipment including clothing, shoe covers, mask, and gloves are sterilized with $75 \%$ ethanol and collected in three layers of medical waste packaging bags. The outer packaging bags should be labelled with "medical waste generation site", department, date, category, and marked as "new coronavirus infection pneumonia" or abbreviated as "new coronavirus" in the special instructions. All items should be treated as normal medical waste after autoclaving. Waste should be immediately transferred outside of the working area through the waste passage. Protective face screens can be treated with $75 \%$ ethanol (30).

\section{Decontamination of nucleic acid}

In order to minimize the possibility of residual nucleic acid contamination, decontamination can be performed as follows:

(I) Medical waste that has been in contact with a specimen, such as the pipette tips, sample tubes, and small centrifuge Eppendorf (EP) tubes, should be treated with a $0.55-1 \%$ sodium hypochlorite (31).

(II) A disinfection treatment of $75 \%$ ethanol or $0.55-1 \%$ sodium hypochlorite solution is used to spray or wipe the biosafety cabinets, work surfaces, pipettes, and other supplies.

(III) The frequency of floor disinfection can be determined according to the amount of work and specimens, but at least once a week is recommended. Ground disinfection methods are the same as floor disinfection.

(IV) The amplification products should be packed tightly in a disposable medical garbage bags and transferred to the amplification product disposal area through the waste passage. The amplification products can also be treated in a specific room, and the amplification products should be immersed in a disinfectant containing a $0.55-1 \%$ Sodium hypochlorite (>1 h treatment is recommended) (31).

\section{Waste disposal management}

The operator should dispose of waste promptly and this should be recorded. The waste should not be removed from 
the laboratory without permission. Medical waste should be treated in accordance with the Administrative Measures on Medical Wastes in Medical and Health Institutions (32). Those that can be incinerated should be burned promptly. If not, they should be transported to a landfill after disinfection.

\section{Discussion}

Safety and quality control are two major issues during molecular testing, especially for highly pathogenic microorganism tests, like SARS-CoV-2. In order to protect laboratory staff and the environment, it is necessary to inactivate SARS-CoV-2 through either chemical or physical methods (33). A 75\% ethanol solution may also be used for inactivation. A lysis buffer is recommended, and may be used instead of a specimen preservation reagent, however, any changes in test procedure will affect the performance of the test (34). There are no consistent opinions about how virus inactivation will affect test sensitivity. Reasons for this lay in the different inactivation methods and specimen preservation reagents. The consensus within the literature suggests that preventing RNA degradation is the most important (35). If the specimen was collected in a virus preservation liquid, human respiratory epithelial cells will be destroyed and the RNase released, which is a major factor in RNA degradation. There is also a general consensus that inactivation through heating will decrease the sensitivity of the test (35). Other researchers have found the effect of RNA degradation will be decrease obviously when the specimen is added to an RNase inhibitor such as guanidine salt (not published officially). Because the lysis buffer contains guanidine salt, it can be used for virus lysis; at the same time, it will provide a protective effect for the RNA.

In theory, specimens can be directly used for RNA isolation when they are stored in a lysis buffer; however, it is hard to confirm whether the virus is inactivated completely using a lysis buffer because there is no conclusive evidence. For safety specimens should be inactivated by both preserving them in a lysis buffer and through heating. It was reported that the Middle East respiratory virus could be inactivated at 56 or $65{ }^{\circ} \mathrm{C}$ effectively (26). So taken together, using lysis buffer in specimen collection and inactivation of the virus through heating ought to protect laboratory staff efficiently. Heat the sample for 20 minutes to inactivate it. The virus inactivation time indicates the time required after a specimen reaches the set temperature. Due to different types of sample collection containers, the time to reach the set temperature is also different and should be tested in advance.

Along with virus inactivation, personal protection is very important. During the whole detection process, level three protection is recommended during testing. However, it is not necessary for all laboratory staff. The staff involved specimen collecting, specimen transportation, reagents preparation and amplification can appropriately decrease the protection level. In this way, it is possible to optimize the use of protective clothes and decrease laboratory staff costs.

Nucleic acid contamination should be avoided. The most suitable substance for decontamination is hydrochloric acid. However, it is rarely used because of its associated danger. A $0.55-1 \%$ sodium hypochlorite solution can destroy nucleic acid effectively (31), so it is recommended that nucleic acid decontamination be done using this solution. It should also be noted that sodium hypochlorite is corrosive; therefore, a clean water flush and then ventilating is necessary after treatment.

There are many methods for the homogenization of sputum, such as using sodium hydroxide (36), proteinase $\mathrm{K}$, phosphate-buffered saline (PBS) and N-acetyl-L-cysteine and sodium citrate (NALC) (37). The Technical Guidelines for the Prevention and Control of New Coronavirus Infections in Medical Institutions recommends the use of a mixed reagent or proteinase $\mathrm{K}$ for homogenizing sputum. A proteinase $\mathrm{K}$ is suitable for sputum homogenization, and using $1 \mathrm{~g} / \mathrm{L}$ proteinase $\mathrm{K}$ is convenient and recommended (16).

A comparison of the predicted coding regions of SARS$C O V-2$ showed that they possessed a similar genomic organization to bat-SL-CoVZC45, bat-SL-CoVZXC21, and $S A R S-C o V$. At least 12 coding regions were predicted, including 1ab, S, 3, E, M, 7, 8, 9, 10b, N, 13, and 14 (38). Detecting more sites will increase sensitivity, but it is hard to report results, and it will increase the cost of the reagent. According to the Technical Guidelines for the Prevention and Control of New Coronavirus Infections in Medical Institutions, we recommend the amplification reagent contains at least two sites of the SARS-COV-2 gene (open reading frame $1 \mathrm{a} / \mathrm{b}$ and nucleocapsid protein or envelope protein E). Meanwhile, an amplification reagent with a large reaction system and large sample loading volume is recommended. In addition, amplification kits with different primer pairs could be used to check the results.

Negative results cannot completely exclude a SARS$\mathrm{CoV}-2$ infection. Sample quality, specimen type, sample collection timing (whether it is in a period of low viral load), along with specimen storage, transportation, and 
processing can affect the test results (39). When the clinical manifestations and other examinations highly suspect a SARS-CoV-2 infection, specimen re-collection or the collection of specimens from other parts of the body and repeating the test is recommended. It is necessary to supply an interpretation for each result; at the same time, suggestions for the next steps are needed.

When the test results are ambiguous, the laboratory can implement the following measures: (I) check whether the whole process has an impact on the sample quality, specimen type, sample collection timing (whether it is in a period of low viral load), along with specimen storage, transportation, and processing. (II) The kits from different manufacturers are utilized for repeating the experiment or using another sensitive method (such as a digital PCR method) to confirm the results further. (III) It is recommended that the clinicians re-collect the specimens for re-testing or utilize different types of samples for testing.

This consensus provides detailed information for the detection of $S A R S-C o V-2$; however, with a greater understanding of the virus and more scientific evidence, some of these areas can be improved. Further study is recommended on the development of new methods for virus inactivation.

\section{Acknowledgments}

This work was published first in the National Medical fournal of China in Chinese.

Funding: None.

\section{Footnote}

Reporting Checklist: The authors have completed the AGREE II reporting checklist. Available at http://dx.doi. org/10.21037/atm-20-4060

Conflicts of Interest: All authors have completed the ICMJE uniform disclosure form (available at http://dx.doi. org/10.21037/atm-20-4060). The authors have no conflicts of interest to declare.

Ethics Statement: The authors are accountable for all aspects of this work, ensuring that questions related to the accuracy or integrity of any part of the work are appropriately investigated and resolved.

Open Access Statement: This is an Open Access article distributed in accordance with the Creative Commons Attribution-NonCommercial-NoDerivs 4.0 International License (CC BY-NC-ND 4.0), which permits the noncommercial replication and distribution of the article with the strict proviso that no changes or edits are made and the original work is properly cited (including links to both the formal publication through the relevant DOI and the license). See: https://creativecommons.org/licenses/by-nc-nd/4.0/.

\section{References}

1. National Health Commission of the People's Republic of China. New Coronavirus Infection Pneumonia Treatment Program (Trial Version 5). 2020.

2. Jiang S, Xia S, Ying T, et al. A novel coronavirus (2019$\mathrm{nCoV}$ ) causing pneumonia-associated respiratory syndrome. Cell Mol Immunol 2020;17:554.

3. Rahman Qureshi UU, Saleem S, Khan A, et al. Outbreak of novel Corona virus (2019-nCoV); implications for travelers to Pakistan. Travel Med Infect Dis 2020;34:101571.

4. Kim JY, Choe P, Oh Y, et al. The First Case of 2019 Novel Coronavirus Pneumonia Imported into Korea from Wuhan, China: Implication for Infection Prevention and Control Measures. J Korean Med Sci 2020;35:e61.

5. Chu DK, Pan Y, Cheng S, et al. Molecular Diagnosis of a Novel Coronavirus (2019-nCoV) Causing an Outbreak of Pneumonia. Clin Chem 2020;66:549-55.

6. Corman VM, Landt O, Kaiser M, et al. Detection of 2019 novel coronavirus (2019-nCoV) by real-time RT-PCR. Euro Surveill 2020;25:2000045.

7. Brouwers MC, Kho M, Browman G, et al. AGREE II: advancing guideline development, reporting, and evaluation in health care. Prev Med 2010;51:421-4.

8. Brouwers MC, Kho M, Browman G, et al. Development of the AGREE II, part 1: performance, usefulness and areas for improvement. CMAJ 2010;182:1045-52.

9. Huang JT, Ran R, Lv Z, et al. Chronological Changes of Viral Shedding in Adult Inpatients with COVID-19 in Wuhan, China. Clin Infect Dis 2020;71:2158-66.

10. Wu J, Liu J, Li S, et al. Detection and analysis of nucleic acid in various biological samples of COVID-19 patients. Travel Med Infect Dis 2020;37:101673.

11. Tan FR, Qiu Y, Xu Z. Bronchoalveolar lavage fluid was used to diagnose two cases of 2019-nCoV infection. Zhonghua Jie He He Hu Xi Za Zhi 2020;43:337-9.

12. Zheng S, Fan J, Yu F, et al. Viral load dynamics and disease severity in patients infected with SARS-CoV-2 in Zhejiang 
province, China, January-March 2020: retrospective cohort study. BMJ 2020;369:m1443.

13. Chen W, Lan Y, Yuan X, et al. Detectable 2019-nCoV viral RNA in blood is a strong indicator for the further clinical severity. Emerg Microbes Infect 2020;9:469-73.

14. National Health Commission of the People's Republic of China. Collection and transfer of WS / T 640-2018 clinical microbiology test specimens. 2018.

15. Sung H, Yong D, Ki C, et al. Comparative Evaluation of Three Homogenization Methods for Isolating Middle East Respiratory Syndrome Coronavirus Nucleic Acids From Sputum Samples for Real-Time Reverse Transcription PCR. Ann Lab Med 2016;36:457-62.

16. National Health Commission of the People's Republic of China. Technical Guidelines for the Prevention and Control of New Coronavirus Infections in Medical Institutions (Fifth Edition). 2020.

17. Centers for Disease Control and Prevention (USA). Interim Guidelines for Collecting, Handling, and Testing Clinical Specimens from Patients Under Investigation (PUIs) for Middle East Respiratory Syndrome Coronavirus (MERS-CoV) - Version 2.1. 2015.

18. National Health Commission of the People's Republic of China. Notice of the General Office of the National Health and Health Commission on the requirements for medical institutions to carry out the detection of new coronavirus nucleic acids. 2020.

19. National Health Commission of the People's Republic of China. Guidelines for laboratory testing techniques for new coronavirus infection in pneumonia (third edition). 2020.

20. General Administration of Quality Supervision, Inspection and Quarantine. GB 19489-2008 General requirements for laboratory biosafety. 2008.

21. Ministry of Health of the People's Republic of China. Regulations on the Transportation of Species or Samples of Highly Pathogenic Microorganisms (Poisons) Infecting Human. 2005.

22. International Civil Aviation Organization. Doc9284-AN / 905 Technical Rules for the Safe Transport of Dangerous Goods by Air. 2017.

23. The State Council of the People's Republic of China. Regulations on the Biosafety Management of Pathogenic Microbiology Laboratories. 2004.

24. Ministry of Health of the People's Republic of China. WS 233-2002 General Guidelines for Biosecurity in Microbiology and Biomedical Laboratories. 2002.

25. Farcet MR, Kreil T. Zika virus is not thermostable: very effective virus inactivation during heat treatment (pasteurization) of human serum albumin. Transfusion 2017;57:797-801.

26. Leclercq I, Batéjat C, Burguière A, et al. Heat inactivation of the Middle East respiratory syndrome coronavirus. Influenza Other Respir Viruses 2014;8:585-6.

27. Ministry of Health of the People's Republic of China. Guidelines for clinical gene amplification testing in medical institutions. 2010.

28. National Health Commission of the People's Republic of China. Guidelines for the use of common medical protective equipment in the protection of pneumonia caused by new coronavirus (for trial implementation). 2020.

29. "Xiehe New Coronavirus PP, Manual" editorial team. Xiehe New Coronavirus Pneumonia Protection Manual. 2020.

30. General Administration of Quality Supervision, Inspection and Quarantine. New Coronavirus Pneumonia Prevention and Control Program (Fourth Edition). 2020.

31. Fischer M, Renevey N, Thür B, et al. Efficacy Assessment of Nucleic Acid Decontamination Reagents Used in Molecular Diagnostic Laboratories. PLoS One 2016;11:e0159274.

32. Ministry of Health of the People's Republic of China. Medical Waste Management Measures for Medical Institutions. 2003.

33. Kratzel A, Todt D, V'kovski P, et al. Inactivation of Severe Acute Respiratory Syndrome Coronavirus 2 by WHORecommended Hand Rub Formulations and Alcohols. Emerg Infect Dis 2020;26:1592-5.

34. Chen H, Wu R, Xing Y, et al. Influence of Different Inactivation Methods on Severe Acute Respiratory Syndrome Coronavirus 2 RNA Copy Number. J Clin Microbiol 2020;58:e00958-20.

35. Pan Y, Long L, Zhang D, et al. Potential FalseNegative Nucleic Acid Testing Results for Severe Acute Respiratory Syndrome Coronavirus 2 from Thermal Inactivation of Samples with Low Viral Loads. Clin Chem 2020;66:794-801.

36. Padilla E, Manterola J, González V, et al. Comparison of the sodium hydroxide specimen processing method with the C18-carboxypropylbetaine specimen processing method using independent specimens with auramine smear, the MB/BacT liquid culture system, and the COBAS AMPLICOR MTB test. J Clin Microbiol 2005;43:6091-7.

37. Rachow A, Saathoff E, Mtafya B, et al. The impact of repeated NALC/NaOH- decontamination on the performance of Xpert MTB/RIF assay. Tuberculosis (Edinb) 2018;110:56-8. 
38. Lu R, Zhao X, Li J, et al. Genomic characterisation and epidemiology of 2019 novel coronavirus: implications for virus origins and receptor binding. Lancet 2020;395:565-74.

Cite this article as: Liu Z, Tong $\mathrm{Y}, \mathrm{Wu} \mathrm{J}$, Du L, Wei C, Cui W, Cao Y, Chen M, Cai Z, Chen W, Ding H, Guan M, Guo W, Gao C, Hao X, Hu C, Huang S, Jiang Y, Li J, Li P, Li Z, Ming L, Pan S, Shen Z, Su J, Sun Z, Wang H, Wang J, Xu B, Yu N, Zheng L, Zhang Y, Zhang X, Zhang Y, Duan Y, Wang C; on behalf of the Chinese Society of Laboratory Medicine. Chinese Expert Consensus on the Nucleic Acid Detection of SARS-CoV-2. Ann Transl Med 2020;8(24):1631. doi: 10.21037/atm-20-4060
39. Woloshin S, Patel N, Kesselheim A. False Negative Tests for SARS-CoV-2 Infection - Challenges and Implications. N Engl J Med 2020;383:e38. 
Table S1 Full list of clinical questions

\begin{tabular}{|c|c|c|}
\hline \# & Question & Notes and considerations \\
\hline \multicolumn{3}{|c|}{ FOCUS 1. Specimen selecting, collecting, transportation and receiving? } \\
\hline 1 & $\begin{array}{l}\text { What specimens can be used for SARS-COV2 } \\
\text { detection? }\end{array}$ & $\begin{array}{l}\text { Consider: } \\
\text { - Kinds of specimen } \\
\text { - The value of different kinds of specimen }\end{array}$ \\
\hline 2 & How to increase detection positive rate? & - Which measures can be used? \\
\hline 3 & How to take specimen? & - The way of take different kinds of specimen \\
\hline 4 & Labeling of specimen & - What content should be included? \\
\hline 5 & Package of specimen & - How to package the specimen? \\
\hline 6 & Which laboratory can detect SARS-COV2? & - How to confirm which laboratory can perform gene test of SARS-COV2 \\
\hline 7 & Conditions of specimen transportation? & $\begin{array}{l}\text { - Temperature for transportation. } \\
\text { - How to guarantee the safety? }\end{array}$ \\
\hline 8 & Specimen receiving & $\begin{array}{l}\text { - How to receive specimen and take out them from transportation } \\
\text { container? }\end{array}$ \\
\hline
\end{tabular}

FOCUS 2. Nucleic acid isolation and amplification

1 How to pre-treat different kinds of specimen

2 Virus inactivation

3 What should we do after virus inactivation and before nucleic acid isolation?

$4 \quad$ Is one kind of reagent enough?

5 Results analysis

\section{FOCUS 3. quality control}

$1 \quad$ Quality of specimen collecting

2 Specimen transportation

3 How long the specimen can be storage before treatment

$4 \quad$ Setting of control and quality control

$5 \quad$ How to use $75 \%$ ethanol correctly?

6 Aerosols contamination

FOCUS 4. Biosafety management and decotanmination

1 Personal protection

$2 \quad$ Waste proposal

3 Decontamination of nucleic acid

Sample preservation solution should caution

Time and temperature

Treat specimen immediately

How many control and quality control should be used and cautions

It may inhibit the amplification

How to decrease the risk of aerosols formation

- How to protect the staff involved in specimen collecting, transportation and treatment.

- How to protect the staff during performing the test?

- Should the individual who collects the specimen attend training?

- How many people performing the test together is suitable?

- How to package the waste?

- What measures can be taken in terminal disinfection?

- How to treat the used protective equipment (such as clothes, gloves and so on)

- How to treat medical waste which contact with nucleic acid

- How to treat the instruments after test?

- How to clean the floor?

- How to treat the amplification products?

How to ensure the safety of waste treatment? 
Table S2 Literature review topics

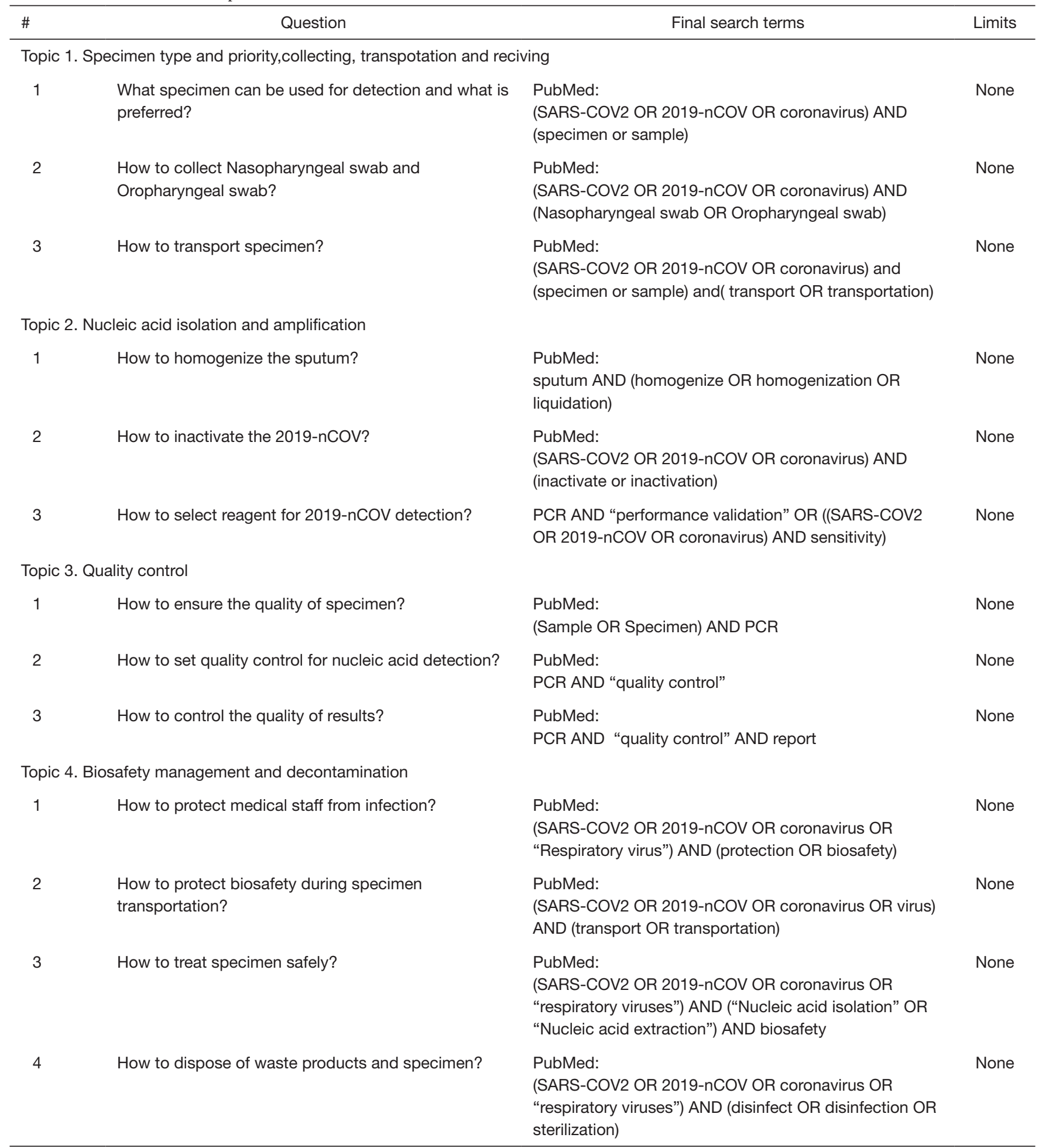


Table S3 Search strategies

\begin{tabular}{|c|c|}
\hline STAGE & INSTRUCTIONS \\
\hline $\begin{array}{l}\text { 1.DEFINE SEARCH TERMS AND } \\
\text { SEARCH STRINGS AND APPLY } \\
\text { LIMITS }\end{array}$ & $\begin{array}{l}\text { Define search terms and search strings } \\
\text { - Construct and test search terms and strings } \\
\text { - Create search strings that incorporate: } \\
\text { o Medical subject headings (MeSH) (https://www.nlm.nih.gov/mesh/) } \\
\text { o Free text key words } \\
\text { - refine and test your search terms } \\
\text { - Use the Search Strategy Recording Form to record your search strategy and number of hits at } \\
\text { each stage, so that it can be replicated }\end{array}$ \\
\hline $\begin{array}{l}\text { 2. SEARCH A SET LIST OF DATA } \\
\text { SOURCES }\end{array}$ & $\begin{array}{l}\text { - Conduct the literature search using a set list of sources, including online databases, online } \\
\text { - Rournals and relevant books } \\
\text { - Decord your results and clearly indicate the data source } \\
\text { - Share the completed Search Strategy Recording Form and Full Search Hits (unscreened) with all } \\
\text { work group members. } \\
\text { Online databases } \\
\text { o PubMed - the mainly database for the literature search. } \\
\text { o Wanfang data online (Chinese) } \\
\text { o VIP databank(Chinese) } \\
\text { o CNKI (Chinese) } \\
\text { Online journal search } \\
\text { - Search the following website: } \\
\text { o http://www.nhc.gov.cn) } \\
\text { o http://www.samr.gov.cn/ }\end{array}$ \\
\hline $\begin{array}{l}\text { 3. IDENTIFY RELEVENT ARTICLES } \\
\text { (SCREENING) }\end{array}$ & $\begin{array}{l}\text { Screening } \\
\text { Identify and assess relevant studies according to the inclusion and exclusion criteria outlined } \\
\text { below. This task occurs in two screening stages: } \\
\text { - Screening stage 1: screen titles/abstracts according to the below exclusion criteria to identify } \\
\text { relevant articles: } \\
\text { o Not relevant to topic of interest } \\
\text { - Screening stage } 2 \text { : for any articles that are deemed relevant in stage } 1 \text { screening, retrieve the full } \\
\text { text to assess more closely against the exclusion criteria below: } \\
\text { Exclude: } \\
\text { o Lack of science } \\
\text { O Incorrect statistical method } \\
\text { o Observational study }\end{array}$ \\
\hline 4. WRITE SUMMARIES & $\begin{array}{l}\text { - extract the key content according to the topics } \\
\text { - list all content and provide them to the work group. }\end{array}$ \\
\hline
\end{tabular}

Table S4a Oxford Grading

\begin{tabular}{llll}
\hline Level & \multicolumn{1}{c}{ sources } & objects & metholds \\
\hline 1 & Guidelines, Consensus, or standard & SARS-COV2 & PCR \\
2 & Data bank (Pubmed, Wanfang or CNKI) & SARS-COV2 & PCR \\
3 & Data bank (Pubmed ,Wanfang or CNKI) & SARS-COV2 & Molecular test (besides PCR) \\
4 & Data bank (Pubmed, Wanfang or CNKI) & Virus (besides SARS-COV2) & Molecular test (besides PCR) \\
5 & Work group member's opinion & & \\
\hline
\end{tabular}

Table S4b Grades of Recommendation

\begin{tabular}{ll}
\hline A & consistent level 1 \\
\hline B & consistent level 2 \\
C & consistent level 3 or 4 \\
D & level 5 evidence \\
\hline
\end{tabular}


China's PLA General Hospital Medical Laborater cor

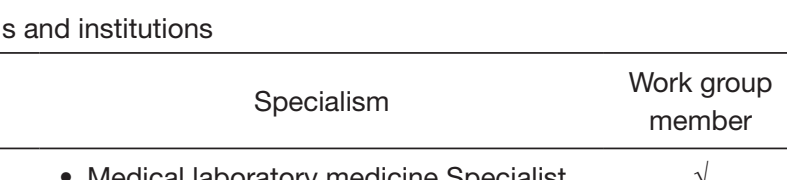

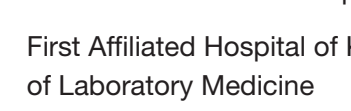

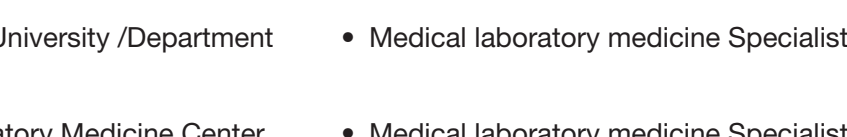

The Second Hospital of Shandeng Universityl Laboratory Medicine

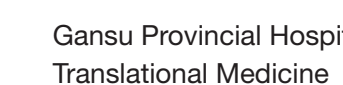

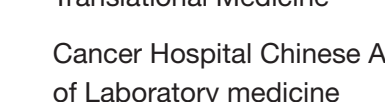

China-Japan Frienssship Hospital Laboratotoy Department

Southwest Hospital Laboratory department
Nantang Hospital of Southern Medical University / Department of
Labobratory Medicine

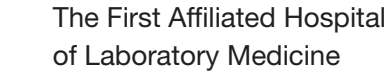

12 People's Hospital of Inner Mongolia AU

13 Huashan Hospital, Fudan University Department of LLaboratory

15 Eastern Hepatobiliar Surger Hosptat, Sceond Militar Medical

16 Air Force Military Medical University / Depa

Guizhou rovinice center for Clinical Labers ong

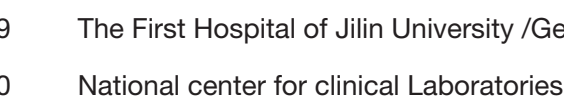

the First Afiliated Hosital of Hunan University of Trad
Medicine/ Medical Laboratory and Pathology Center

22 The First Afiliated Hospitid

23 the First Afiliated Hospital of Zhengzhou Un

24 the First Afiliated Hospital of Nanjing Medical University/ Departm

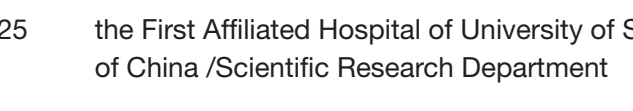

26 Besing frinsshin Hossital, Cap

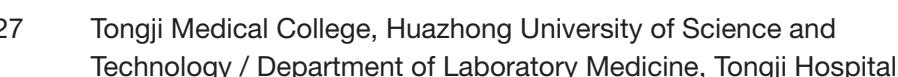

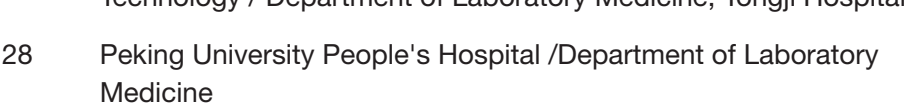

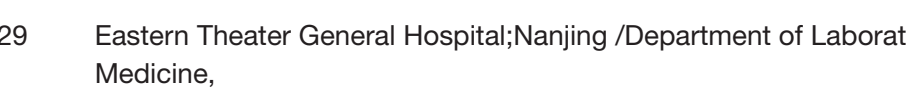

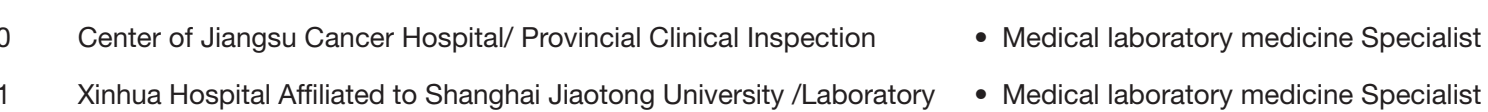

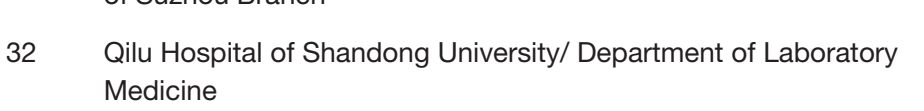

Xiniang Production and Construction Corps Hospital Department of - Medical laboratioy medicine S Specialis

34 Yunnan Key Laboratory of Laboratory Medicine

able Ssb Consensus ressonse a t Dephi Round 1

Statement

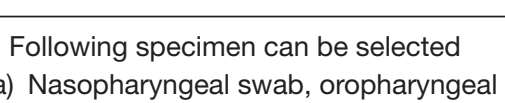

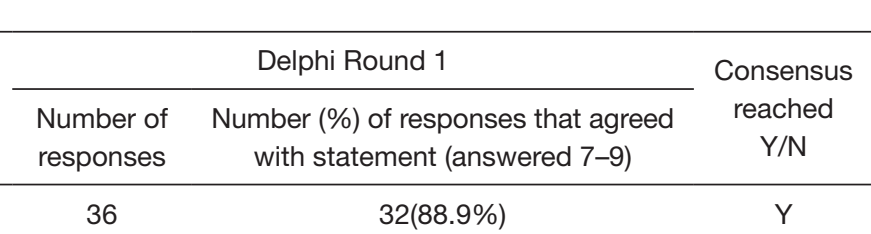

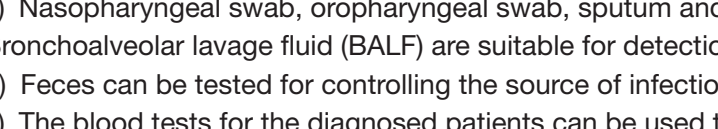
is) The blood tests tor the diagnosed patients can be used to

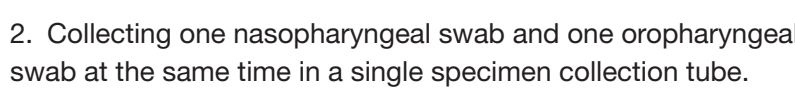

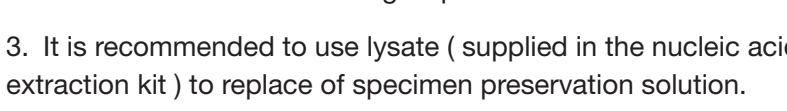

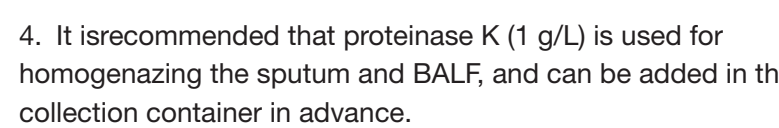

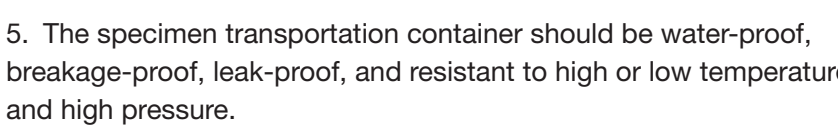

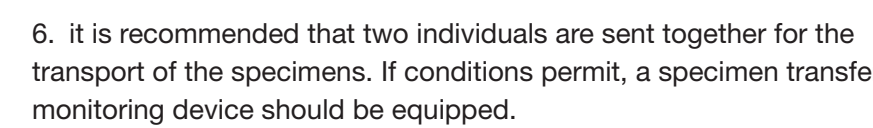

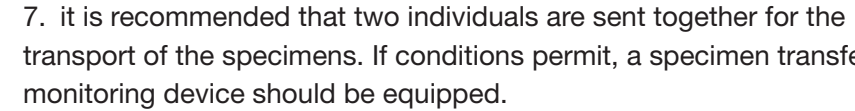

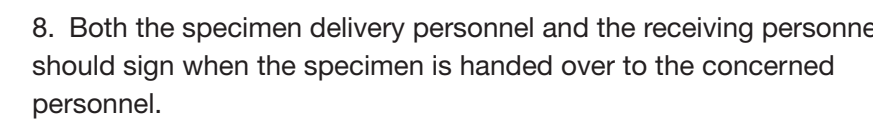

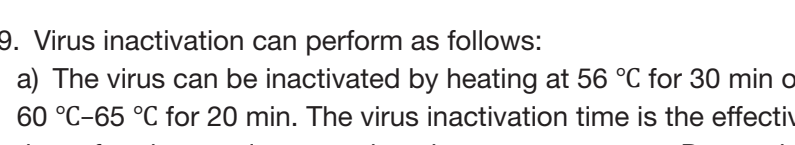

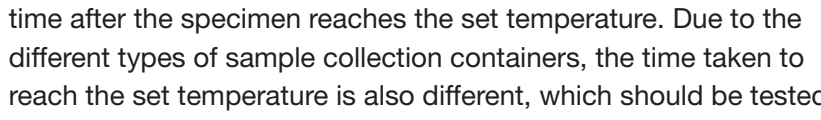

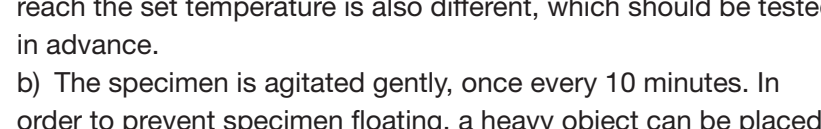

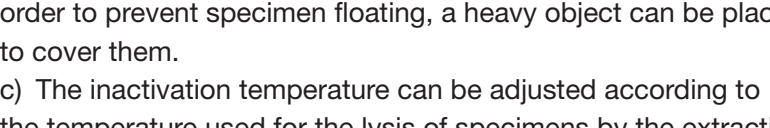

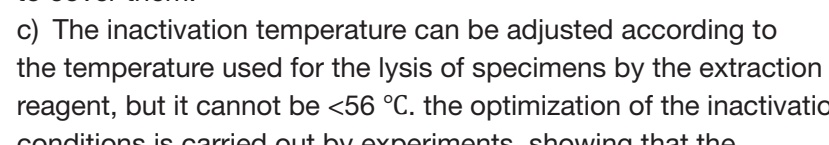

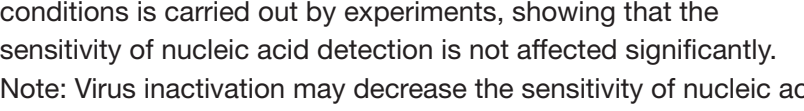

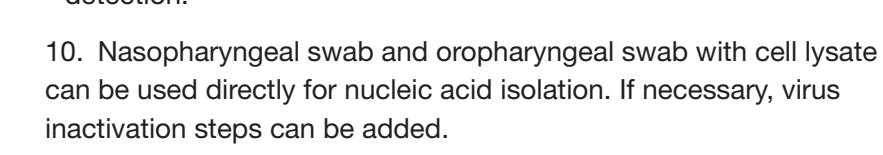

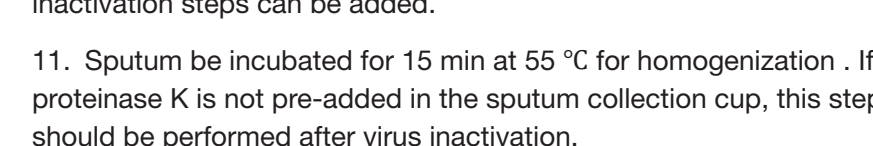

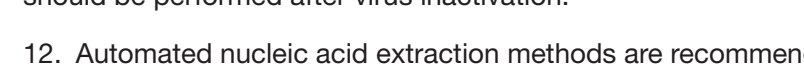

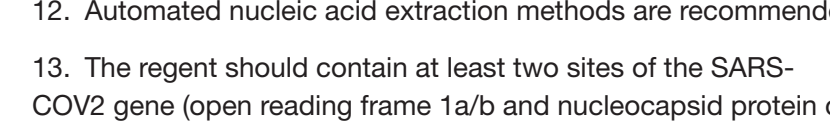
envelope protein $\mathrm{E}$.

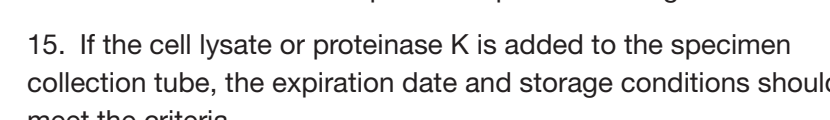

16. Specimens should betrits
shoroten the time of delection

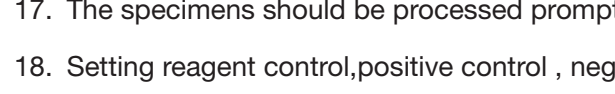

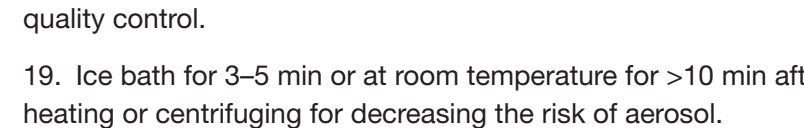

20. A reasonaable decrease in the amount of $75 \%$ ethar

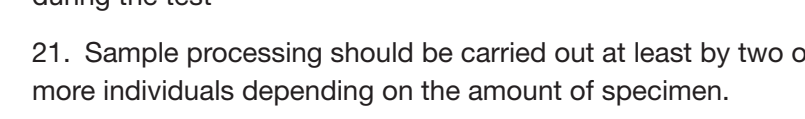

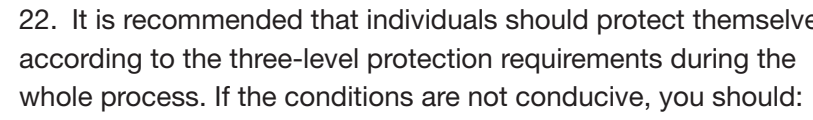

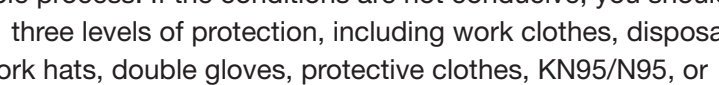

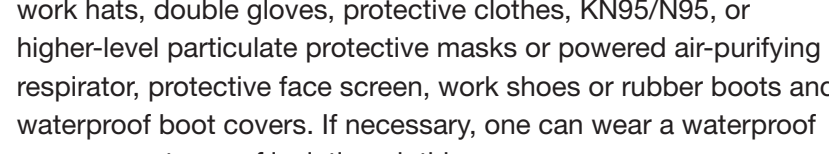

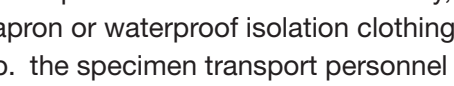

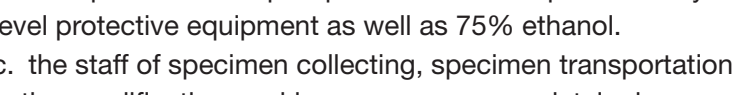

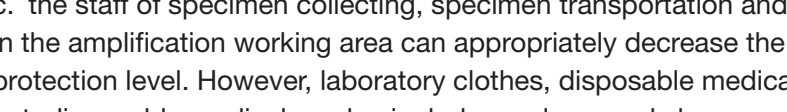

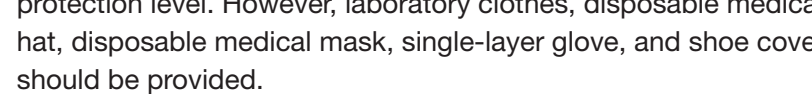

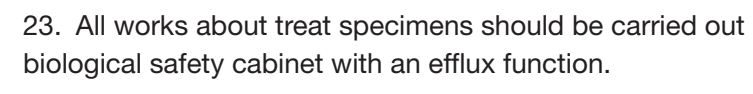

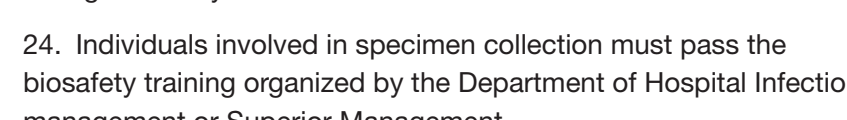

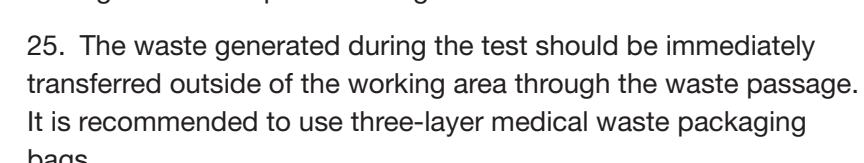

$$
\begin{aligned}
& \text { trans } \\
& \text { It is } \\
& \text { bags } \\
& \text { bag }
\end{aligned}
$$

26. The termina disisinection is carried out using a hydrogen

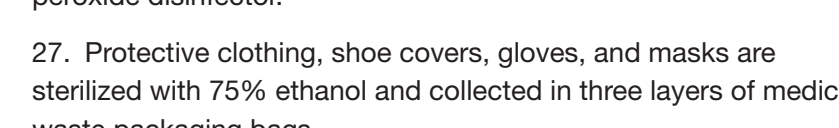

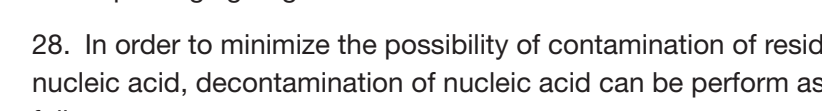

Aoliows:
a) Medical waste should be treated with $0.55-1 \%$ chlorine-

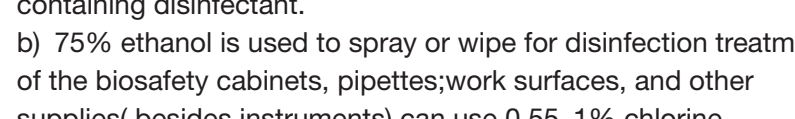

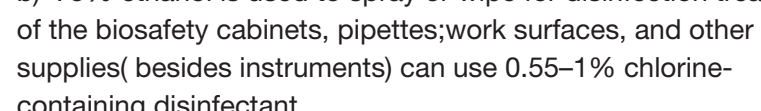

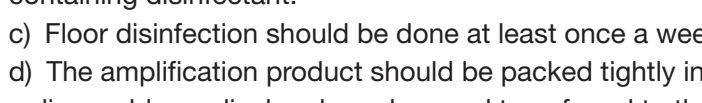

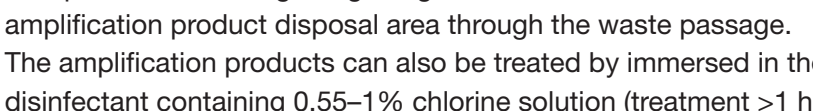




\section{Hospital/Institution}

1 China's PLA General Hospital/ Medical Laboratory Center

2 First Affiliated Hospital of Kunming Medical University /Department of Laboratory Medicine

3 Renmin hospital of Wuhan University /Laboratory Medicine Center Shanghai general Hospital, Shanghai /Laboratory Medicine Center The Second Hospital of Shandong University/ Laboratory Medicine Center

6 Gansu Provincial Hospital /The Institute of Clinical Research and Translational Medicine

7 Cancer Hospital Chinese Academy of Medical Sciences/ Department of Laboratory medicine

8 China-Japan Friendship Hospital/ Laboratory Department

9 Southwest Hospital/ Laboratory department

10 Nanfang Hospital of Southern Medical University /Department of Laboratory Medicine

11 The First Affiliated Hospital of Xi'an Jiaotong University/ Department of Laboratory Medicine

12 People's Hospital of Inner Mongolia Autonomous Region / Department of Laboratory Medicine

13 Huashan Hospital, Fudan University /Department of Laboratory Medicine

14 Zhongshan Hospital, Fudan University /Department of Laboratory Medicine

15 Eastern Hepatobiliary Surgery Hospital, Second Military Medical University /Department of Laboratory Medicine,

16 Air Force Military Medical University / Department of Laboratory Medicin

17 960th Hospital of Chinese PLA /Department of Laboratory Diagnosis

18 Guizhou province center for Clinical Laboratory

19 The First Hospital of Jilin University /Gene Diagnostic Center

20 National center for clinical Laboratories

21 the First Affiliated Hospital of Hunan University of Traditional Chinese Medicine/ Medical Laboratory and Pathology Center

22 the First Affiliated Hospital of Xi'an Medical College /Department of Laboratory Medicine

23 the First Affiliated Hospital of Zhengzhou University /Department of Laboratory Medicine

24 the First Affiliated Hospital of Nanjing Medical University /Departmen of Laboratory Medicine

25 the First Affiliated Hospital of University of Science and Technology of China /Scientific Research Department

26 Beijing Friendship Hospital, Capital Medical University/ Department of Laboratory Medicine

$27 \quad$ Tongji Medical College, Huazhong University of Science and Technology / Department of Laboratory Medicine, Tongji Hospita

28 Peking University People's Hospital /Department of Laboratory Medicine

29 Eastern Theater General Hospital;Nanjing /Department of Laboratory Medicine,

30 Center of Jiangsu Cancer Hospital/ Provincial Clinical Inspection

31 Xinhua Hospital Affiliated to Shanghai Jiaotong University / Laboratory of Suzhou Branch

32 Qilu Hospital of Shandong University/ Department of Laboratory Medicine

33 Xinjiang Production and Construction Corps Hospital/ Department of laboratory medicine

34 Yunnan Key Laboratory of Laboratory Medicine

- Medical laboratory medicine Specialist

- Medical laboratory medicine Specialist

- Medical laboratory medicine Specialist

- Medical laboratory medicine Specialist

- Medical laboratory medicine Specialist

- Medical laboratory medicine Specialist

- Medical laboratory medicine Specialist

- Medical laboratory medicine Specialist

- Medical laboratory medicine Specialist

- Medical laboratory medicine Specialist

- Medical laboratory medicine Specialist

- Medical laboratory medicine Specialist

- Medical laboratory medicine Specialist

- Medical laboratory medicine Specialist

- Medical laboratory medicine Specialist

- Medical laboratory medicine Specialis

- Medical laboratory medicine Specialis

- Medical laboratory medicine Specialist

- Medical laboratory medicine Specialist

- Medical laboratory medicine Specialist

- Medical laboratory medicine Specialist

- Medical laboratory medicine Specialist

- Medical laboratory medicine Specialist

- Medical laboratory medicine Specialist

- Medical laboratory medicine Specialist

- Medical laboratory medicine Specialist

- Medical laboratory medicine Specialist

- Medical laboratory medicine Specialist

- Medical laboratory medicine Specialist

- Medical laboratory medicine Specialist

- Medical laboratory medicine Specialist

- Medical laboratory medicine Specialist

- Medical laboratory medicine Specialist

- Medical laboratory medicine Specialist Work group member

Table S6b Consensus response at Delphi Round 2

\begin{tabular}{|c|c|c|c|}
\hline \multirow[b]{2}{*}{ Statement } & \multicolumn{2}{|r|}{ Delphi Round 1} & \multirow{2}{*}{$\begin{array}{c}\text { Consensus } \\
\text { reached } \\
\mathrm{Y} / \mathrm{N}\end{array}$} \\
\hline & $\begin{array}{l}\text { Number of } \\
\text { responses }\end{array}$ & $\begin{array}{l}\text { Number (\%) of responses that agreed } \\
\text { with statement (answered 7-9) }\end{array}$ & \\
\hline $\begin{array}{l}\text { 9. The virus can be inactivated by heating at } 56^{\circ} \mathrm{C} \text { for } 30 \text { min or } \\
60^{\circ} \mathrm{C}-65^{\circ} \mathrm{C} 20 \text { min. Specimen preservation solution should contain } \\
\text { RNA protectant. }\end{array}$ & 36 & $34(94.4 \%)$ & Y \\
\hline $\begin{array}{l}\text { 21. Sample processing should be carried out at least by two or more } \\
\text { individuals. }\end{array}$ & 36 & $36(100 \%)$ & Y \\
\hline $\begin{array}{l}\text { 22. It is recommend that taking three levels of protection. If } \\
\text { necessary, one can wear a waterproof apron or waterproof isolation } \\
\text { clothing. }\end{array}$ & 36 & $36(100 \%)$ & Y \\
\hline $\begin{array}{l}\text { 26. The terminal disinfection is carried out using a hydrogen peroxide } \\
\text { disinfector or other metholds. }\end{array}$ & 36 & $36(100 \%)$ & Y \\
\hline
\end{tabular}


Table S7 Quick reference guide to guidance statements

Specimen type and priority ,collecting, transportation and handover

1. Following specimen can be selected

a) Nasopharyngeal swab, oropharyngeal swab, sputum and Bronchoalveolar lavage fluid (BALF) are suitable for detection.

b) Feces can be tested for controlling the source of infection.

c) The blood tests for the diagnosed patients can be used to monitor the therapeutic effect (further research support is required).

2. Collecting one nasopharyngeal swab and one oropharyngeal swab at the same time in a single specimen collection tube.

3. It is recommended to use lysate ( supplied in the nucleic acid extraction kit) to replace of specimen preservation solution.

4. It is recommended that proteinase $\mathrm{K}(1 \mathrm{~g} / \mathrm{L})$ is used for homogenizing the sputum and BALF, and can be added in the collection container in advance.

5. Specimens should be sent to a laboratory that is qualified to perform SARS-COV2 nucleic acid testing and approved by the health administrative organization.

6. The specimen transportation container should be water-proof, breakage-proof, leak-proof, and resistant to high or low temperature and high pressure.

7. it is recommended that two individuals sent together for the specimen transportation. If conditions permit, a specimen transfer monitoring device should be equipped.

8. Both the specimen delivery personnel and the receiving personnel should sign when the specimen is handed over to the concerned personnel.

Nucleic acid isolation and amplification

9. The virus can be inactivated by heating at $56{ }^{\circ} \mathrm{C}$ for $30 \mathrm{~min}$ or $60{ }^{\circ} \mathrm{C}-65^{\circ} \mathrm{C} 20 \mathrm{~min}$. Specimen preservation solution should contain RNA protectant.

10. Nasopharyngeal swab and oropharyngeal swab with cell lysate can be used directly for nucleic acid isolation. If necessary, virus inactivation steps can be added.

11. Sputum is incubated for $15 \mathrm{~min}$ at $55^{\circ} \mathrm{C}$ for homogenization. If proteinase $\mathrm{K}$ is not pre-added in the sputum collection cup, this step should be performed after virus inactivation.

12. Automated nucleic acid extraction methods are recommended.

13. The regent should contain at least two sites of the SARS-COV2 gene (open reading frame $1 \mathrm{a} / \mathrm{b}$ and nucleocapsid protein or envelope protein E).

14. The results should be reported as positive or negative .

Quality control

15. If the cell lysate or proteinase $\mathrm{K}$ is added to the specimen collection tube, the expiration date and storage conditions should meet the criteria.

16. Specimens should be transported to the hospital within $2-4 \mathrm{~h}$ to shorten the time of detection .

17. The specimens should be processed promptly.

18. Setting reagent control,positive control, negative and positive quality control.

19. Ice bath for 3-5 min or at room temperature for $>10$ min after heating or centrifuge for decreasing the risk of aerosol.

20. A reasonable decrease in the amount of $75 \%$ ethanol used during the test.

Biosafety management and decontamination of nucleic acid

21. Sample processing should be carried out at least by two or more individuals.

22. It is recommended to take three levels of protection. If necessary, one can wear a waterproof apron or waterproof isolation clothing

23. All works about treat specimens should be carried out in a biological safety cabinet with an efflux function.

24. Individuals involved in specimen collection must pass the biosafety training organized by the Department of Hospital Infection Management or Superior Management.

25. The waste generated during the test should be immediately transferred outside of the working area through the waste passage. It is recommended to use three-layer medical waste packaging bags.

26. The terminal disinfection is carried out using a hydrogen peroxide disinfector or other methods.

27. Protective clothing, shoe covers, gloves, and masks are sterilized with $75 \%$ ethanol and collected in three layers of medical waste packaging bags.

28. In order to minimize the possibility of contamination of residual nucleic acid, decontamination of nucleic acid can be perform as follows:

a) Medical waste should be treated with $0.55-1 \%$ chlorine-containing disinfectant

b) $75 \%$ ethanol is used to spray or wipe for disinfection treatment of the biosafety cabinets, pipettes;work surfaces, and other supplies( besides instruments) can use $0.55-1 \%$ chlorine-containing disinfectant.

c) Floor disinfection should be done at least once a week

d) The amplification product should be packed tightly in a disposable medical garbage bag and transferred to the amplification product disposal area through the waste passage. The amplification products can also be treated by immersed in the disinfectant containing $0.55-1 \%$ chlorine solution ( $>1 \mathrm{~h}$ treatment $>1 \mathrm{~h}$ is recommended).

29. The operator should dispose ofthe waste promptly and this should be recorded. The waste should not be removed from the laboratory without permission. Medical waste should be treated in accordance with the Administrative Measures on Medical Wastes in Medical and Health Institutions. 